\title{
Pistonlu Basınç Standartlarında Piston ve Silindir Arasındaki Boşlukta Oluşan Basınç Dağılımının Hesaplanması
}

\author{
${ }^{* 1}$ Ahmet Türk \\ ${ }^{1}$ TÜBİTAK UME, Gebze-Kocaeli, Türkiye
}

\section{Özet}

Pistonlu basınç standarları basınç metrolojisinde referans basınç üretilmesinde kullanılmaktadır. $\mathrm{Bu}$ cihazların en önemli bileşeni piston-silindir ünitesidir. Referans basıncın hassas bir şekilde hesaplanabilmesi için piston-silindir ünitesinin basınç altındaki efektif alan değerine gereksinim vardır. Efektif alan değeri genellikle deneysel olarak hesaplanan $\mathrm{A}_{0}\left(20^{\circ} \mathrm{C}\right.$ sıcaklık ve $1 \mathrm{~atm}$ basınç altındaki efektif alan değeri) ve basınç distorsiyon katsayısı ile bulunmaktadır. Karşılıklı akışa dayalı yöntem olarak bilen bu deneysel metotta referans bir cihaza gereksinim vardır. Bu yönteme alternatif olarak boyutsal ölçümler yöntemi ile $A_{0}$ değeri hesaplanabilmektedir. Ancak basınç distorsiyon katsayısının belirlenebilmesi için boyutsal ölçümler tek başına yeterli değildir. Boyutsal ölçümlere ek olarak, pistonsilindir ünitesinin farklı basınçlar altında, piston ve silindir ünitesi arasındaki basınç dağılımının bilinmesi gereklidir. Bu çalışmada piston ve silindir arasındaki boşlukta farklı basınçlarda oluşan basınç dağılımı ref. 5 de açıklanan yöntem ile hesaplanmıştır.

Anahtar Kelimeler: Piston-silindir ünitesi, Basınç distorsiyon katsayısı, Basınç dağılımı.

\begin{abstract}
Pressure balances are generally used to generate reference pressure in pressure metrology. The most essential part of pressure balances is piston-cylinder unit. For precise pressure measurements, the effective area of piston cylinder unit under a pressure load should be well-known. Effective area can be calculated by using $\mathrm{A}_{0}$ (effective area at $20^{\circ} \mathrm{C}$ and $1 \mathrm{~atm}$ pressure) and pressure distortion coefficient. $\mathrm{A}_{0}$ and pressure distortion coefficient can be determined empirically. In addition to the empirical method, $\mathrm{A}_{0}$ can be calculated by means of dimensional measurement method. However, dimensional measurements are not enough to determine the pressure distortion coefficient. Besides to geometric calibration of piston and cylinder, pressure distribution through the gap between piston and cylinder should be known. In this study, the pressure distributions are calculated at different pressure values by using the method given in ref. 5 .
\end{abstract}

Key words: Piston-cylinder unit, Pressure distotion coefficient, Pressure distribution.

\section{Giriș}

Pistonlu basınç standartları yüksek doğruluklu referans basınç üretmede sıklıkla tercih edilen referans cihazlardandır. Pistonlu basınç standartlarının en önemli bileşeni piston-silindir ünitesidir. $\mathrm{Bu}$ cihazlarda üretilen basıncın hesaplanabilmesi için piston-silindir ünitesinin efektif alan değeri bilinmelidir. Efektif alan piston-silindir ünitesinin geometrik özelliklerine ve üretildiği malzemeye oldukça bağlıdır. Genellikle kobalt katkılı tungsten karbürden yapılan piston-silindir ünitelerinin efektif alan değeri sıcaklık ve basınçla değişim gösterir. Bu nedenle piston-silindir ünitelerinin kalibrasyonu $20^{\circ} \mathrm{C}$ ve 1 atm basınç altındaki efektif alan değerinin $\left(\mathrm{A}_{0}\right)$ ve basınç distorsiyon

*Sorumlu Yazar: Adres: Tübitak UME, Ulusal Metroloji Enstitüsü, Gebze-Kocaeli, Türkiye. E-mail adres: turk.ahmet@ tubitak.gov.tr, Telefon: +902626795000 
katsayısının hesaplanmasını içerir. Pistonlu basınç standarlarının kalibrasyonu genellikle karşılıklı akışa dayalı yöntem ile gerçekleştirilir. Burada izlenebilir referans pistonlu basınç standardına gereksinim vardır. Kalibre edilecek cihaz referans cihaz ile ortak basınç hattına bağlanır ve her iki cihaz kalibre edilecek cihazın ölçüm aralığını kapsayacak şekilde farklı basınç noktalarında karşılaştırılır. Ancak $A_{0}$ değeri, boyutsal ölçümler yöntemi ile başka referans pistonlu basınç standardına gereksinim olmadan da belirlenebilir. Burada Dadson Theory kullanılmaktadır [1]. Diğer taraftan pistonlu basınç standardına ait basınç distorsiyon katsayısı ise tek basına Dadson Theory ile belirlenemez. Basınç distorsiyon katsayısının belirlenebilmesi için sonlu elemanlar yöntemine dayalı bir metot kullanılabilmektedir [2-4]. Buradaki ilk aşama farklı basınç noktalarında piston silindir arasındaki basınç dağılımının hesaplanmasıdır. Bu amaçla ref. 5'de açıklanan yöntem kullanılarak nominal $5 \mathrm{~mm}^{2}$ efektif alana sahip olan pistonlu basınç standardı için hesaplamalar yapılmıştır. Daha sonraki çalışmalarda ref. 4'de verilen yöntem aynı pistonsilindir ünitesi için hesaplanıp sonuçlar karşılaştırılacaktır.

\section{Piston-Silindir Ünitesi}

Hesaplamalarda kullanılan piston silindir ünitesi nominal $5 \mathrm{~mm}^{2}$ efektif alana sahip olup hidrolik basınç ölçümlerinde kullanılmaktadır. Ortalama piston yarıçapı $1.248117 \mathrm{~mm}$, ortalama silindir yarıçapı ise $1.248457 \mathrm{~mm}$ 'dir. Piston ve silindir arasındaki boşluk $0.000340 \mathrm{~mm}$ mertebesindedir.

\section{Yöntem}

Piston ve silindir arasındaki boşlukta oluşan basınç dağılımının hesaplanmasında ref. 5 de açıklanan yöntem kullanılmıştır. Bu yönteme göre, öncelikle piston ve silindir arasındaki boşluk katmanlara bölünür. Piston ve silindir arasındaki basınç dağılımı pistonun alt yüzeyinden başlanarak mesafeyle orantılı olarak azaltılır ve pistonun üst yüzeyinde atmosfer basıncına eşitlenir. Her bir katmanın orta noktasındaki bu basınç değerleri 1 numaralı eşitlikte yerine konularak akışkana ait viskozite değerleri hesaplanır [4]. Kullanılan akışkan di(2)-ethyl-hexylsebacate 'dir.

$$
\eta=0.021554 \cdot\left(1+1.90036 \cdot 10^{-3} \cdot p\right)^{8.8101}, \mathrm{p} \leq 500 \mathrm{MPa}
$$

Daha sonra her katmandaki basınç kaybı, 2 numaralı denklemden faydalanılarak, debi cinsinden ifade edilir [5].

$$
\mathrm{F}=\frac{\mathrm{P}}{\mathrm{L}} \cdot \frac{1}{\eta} \cdot \mathrm{K}
$$

Burada $\mathrm{F}$ debi, L piston ve silindir arasındaki boşluğun uzunluğu, $\eta$ dinamik viskozite ve K pistonsilindir ünitesine ait bir sabittir. Bu sabit piston ve silindire ait boyutsal ölçüm verilerinden yararlanılarak hesaplanır. Hesaplamalarda elde edilen basınç kayıpları toplanır ve bu kayıpların toplamı pistonun alt ve üstündeki toplam basınç farkına eşitlenir. Bu eşitliğin çözülmesi ile beraber piston ve silindir arasındaki akışkanın debi değeri elde edilir. Elde edilen debi değeri kullanılarak her katmandaki basınç değeri hesaplanır. Yukarıda gerçekleştirilen işlemler ardışık iterasyonlar 
sonucunda elde edilen basınç değerleri arasındaki fark önemsiz olana kadar sürdürülür. Hesaplanan basınç değerlerinin yeteri kadar yakınsaması durumunda piston ve silindir arasındaki basınç dağılımı elde edilmiş olur [5].

\section{Hesaplama}

Yapılan hesaplamalarda piston ve silindir arasındaki boşluk sabit genişlikli $(0.000340 \mathrm{~mm})$ olarak kabul edilmiştir. Boşluk eşit genişlikli 500 katmana ayrılmıştır. $100 \mathrm{MPa}, 200 \mathrm{MPa}, 300 \mathrm{MPa}$ ve $400 \mathrm{MPa}$ basınçları için piston ve silindir arasındaki basınç dağılımları hesaplanmıştır. Yapılan hesaplamalarda piston ve silindir arasındaki boşluk sabit olup, basınç altında boşlukta meydana gelen değişim hesaba katılmamıştır. Hesaplamalarda yakınsama kriteri olarak ardışık çevrimlerdeki basınç farkının $1 \mathrm{~Pa}$ değerine eşit veya daha düşük olması kabul edilmiştir.

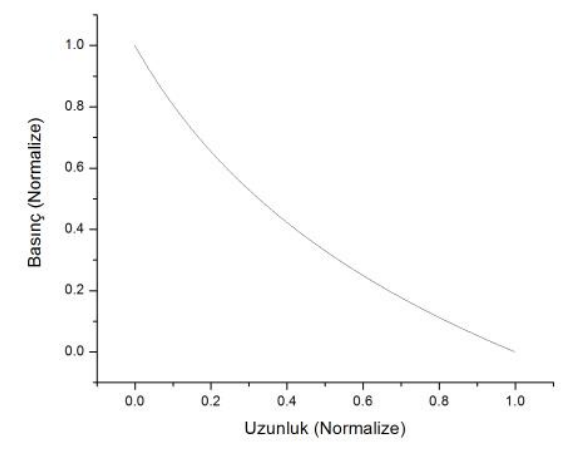

a

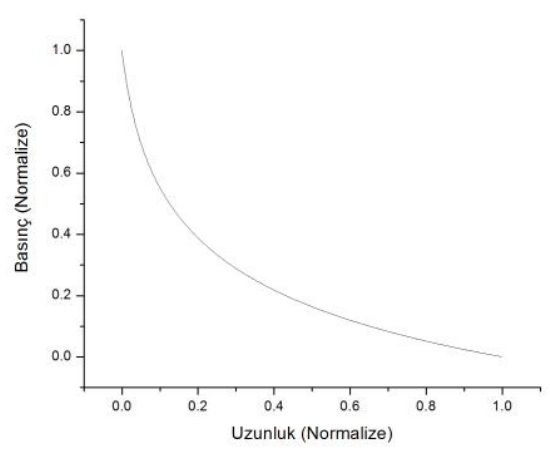

$\mathrm{c}$

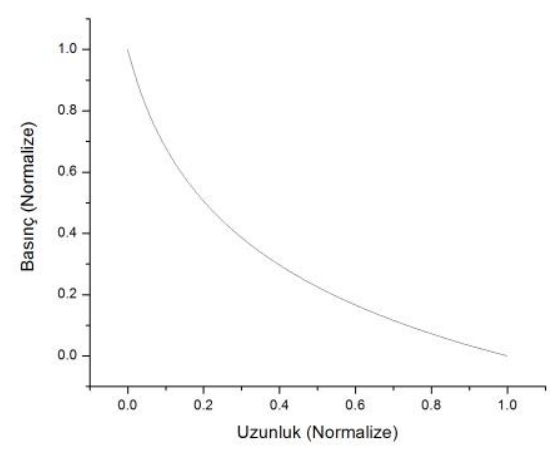

b

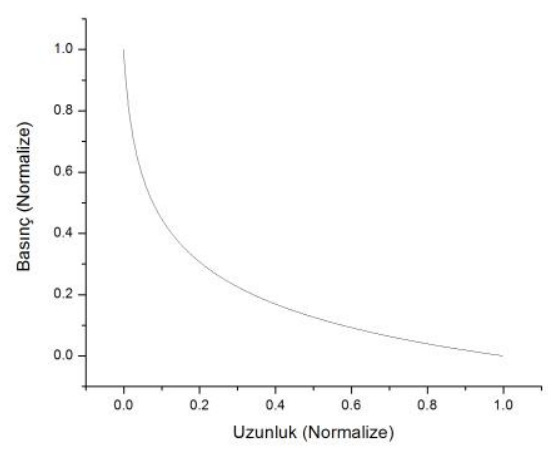

d

Şekil 1: $100 \mathrm{MPa}$ (a), $200 \mathrm{MPa}$ (b), $300 \mathrm{MPa}$ (c) ve $400 \mathrm{MPa}$ (d) basınç değerlerinde piston-silindir arasındaki boşukta hesaplanan basınç dağılımları

Hesaplamalar Octave bilgisayar programı kullanılarak gerçekleştirilmiştir [6]. Yapılan hesaplamalara ait grafikler Şekil 1'de gösterilmektedir. $100 \mathrm{MPa}$ basınç değerinde piston-silindir arasındaki boşluk lineere daha yakın iken, basıncın artmasıyla boşlukta meydana gelen basınç 
dağılımı lineerlikten uzaklaşmaktadır. Örneğin; $100 \mathrm{MPa}$ basınç değerinde piston-silindir arasındaki boşluğun yarısında basınç değeri yaklaşık olarak 65\% oranında azalırken, $200 \mathrm{MPa}$ değerinde bu azalma oranı 80\%, $300 \mathrm{MPa}$ değerinde $85 \%$ ve $400 \mathrm{MPa}$ değerinde $90 \%$ civarındadır.

\section{Sonuç}

Pistonlu basınç standartlarında farklı basınçlarda yapılan çalışmalar sonucunda piston-silindir arasındaki boşlukta meydana gelen basınç dağılımı Stuart [5] tarafından kullanılan yöntem ile hesaplanmıştır. Yapılan hesaplamalarda piston-silindir arasındaki boşluğun sabit genişlikli olduğu varsayılmıştır. Yapılan hesaplamalar basınç değerinin artmasıyla basınç dağılımının doğrusallıktan uzaklaştığını göstermektedir. Özellikle $400 \mathrm{MPa}$ basınç değerinde piston ve silindir arasındaki boşluğun yarısında basıncın $50 \mathrm{MPa}$ değerine kadar düştüğü görülmüştür.

\section{Yapılacak Çalışmalar:}

Yukarıdaki çalışmada piston ve silindir arasındaki boşluk sabit kabul edilmiş olup basınç altında bu boşlukta meydana gelen değişim hesaba katılmamıştır. Ancak yüksek basınç altında pistonun sıkışması ve silindirin genişlemesiyle beraber boşluk profilinde değişmeler meydana gelecektir. Bu durumun piston-silindir arasındaki boşlukta meydana gelen basınç dağılımını etkilemesi beklenmektedir. Bir sonraki çalışmada basınç dağılımının piston ve silindir arasındaki boşlukta meydana getirdiği değişim yapısal olarak incelenecek ve değişimin basınç dağılımını nasıl etkilediği hesaplanacaktır. Elde edilen basınç dağılımı pistonlu basınç standartlarının basınç distorsiyon katsayısının hesaplanmasında kullanılacaktır.

\section{Kaynaklar}

[1] Dadson R. S., Lewis S. L. and Peggs G. N., The Pressure Balance:Theory and Practice, London: HMSO, 1982.

[2] Molinar G., Sabuga W., Robinson G. and Legras J. C., Comparison of methods for calculating distortion in pressure balances up to $400 \mathrm{MPa}$-EUROMET project \#256 Metrologia 35 (1998) 739-59.

[3] Sabuga W., Molinar G., Buonanno G., Esward T., Rabault T. and Yagmur L. Calculation of the distortion coefficient and associated uncertainty of PTB and LNE 1 GPa pressure balances using finite element analysis-EUROMET project 463 Metrologia 42 (2005) 202-6.

[4] Sabuga W., Molinar G., Buonanno G., Esward T., Legras J. C., Yagmur L., Finite element method used for calculation of the distortion coefficient and associated uncertainty of a PTB 1 GPa pressure balance-EUROMET project 463, Metrologia 43 (2006) 311-325.

[5] Stuart P. R., The influence of fluid viscosity on the distortion of piston-cylinder assemblies in pressure balances High Pressure Metrology, BIPM Monographie 89/1 (1989) 31-40.

[6] GNU Octave, erişim:17 Eylül 2019, https://www.gnu.org/software/octave/index. 